\title{
THE CONTINUITY STRATEGY, HUMAN BEHAVIOR, AND BEHAVIOR ANALYSIS
}

\author{
SIMON DYMOND \\ APU, Cambridge

\section{BRYAN ROCHE and DERMOT BARNES-HOLMES National University of Ireland, Maynooth}

\begin{abstract}
In behavior analysis, continuity refers to the assumption of a similarity of behavioral principles or processes between nonhumans and humans, which is often considered to be a fundamental postulate of the field. The present paper outlines a more recent view of the continuity assumption as an epistemological tool or research strategy. Researchers employing this strategy attempt to replicate with humans already-identified behavioral principles from nonhuman research prior to their application to socially relevant issues in natural settings. This form of the continuity strategy has flourished, despite demonstrable differences between nonhuman and human behavior, firstly in the study of performance on schedules of reinforcement and more recently in the study of derived stimulus relations. The implications of research on derived stimulus relations for the differing theoretical accounts of the continuity strategy are discussed.
\end{abstract}

The term "continuity" is derived from the French, continuité, and the Latin, contuitas-tatis, for continuous. Dictionary definitions refer to "the state of being continuous," "an unbroken succession," or "a logical sequence." Thus, continuity is used to describe a sequence of related events or phenomena. In behavior analysis, the term is typically used in a nontechnical manner to refer to the assumption of a similarity of psychological principles between nonhumans and humans. Indeed, this assumption might be considered a cornerstone of the behavior-analytic approach to science. According to Skinner (1953):

Human behavior is distinguished by its complexity, its variety, and its greater accomplishments, but the basic processes [shared with nonhumans] are not therefore necessarily different. Science

Preparation of this article was supported by an APU School of Applied Sciences Research Sabbatical awarded to Simon Dymond. Some earlier thoughts were presented at the Spring Meeting of the Behaviour Analysis in Ireland Group, Jordanstown, May 2000. Many thanks to Bill Dube, Ruth Anne Rehfeldt, Veronica Cullinan, and two anonymous reviewers for helpful comments. Address correspondence to Simon Dymond, Department of Psychology, APU, East Road, Cambridge, CB1 1PT, UK. (E-mail: s.dymond@apu.ac.uk). 
advances from the simple to the complex; it is constantly concerned with whether the processes and laws discovered at one stage are adequate for the next. It would be rash to assert at this point that there is no essential difference between human behavior and the behavior of lower species; but until an attempt has been made to deal with both in the same terms, it would be equally rash to assert that there is. (p. 38)

The assumption of continuity between nonhumans and humans has guided and continues to guide the research activity of behavior analysts despite there being little evolutionary justification for such an assumption. The evolutionarily sensible form of continuity holds that "new contains old" and thus it can not be assumed that "old contains new." Evolutionary theory would be rendered absurd if this were the case because evolutionary continuity flows forward in time, not backward. Metaphorically, studying distantly related species is akin to viewing the tips of evolutionary branches, not the rungs of a single evolutionary ladder. As such, evolution progresses outward, from the point at which different species differentiated, to the present containing features of both new and old. In this way, discontinuity between humans and nonhumans would in no way contradict a biologically sensible form of the continuity assumption (Hayes, Barnes-Holmes, \& Roche, 2001a, p. 145). Indeed, although biological continuity provided the inspiration for the evolutionary postulation of psychological continuity between species, it does not itself depend on the assumptions of evolution for justification. Thus, biological continuity would assume no difference between species, pending empirical evidence to the contrary. We will return to this issue in greater detail. The important point here is that uncertainty and disagreement over the precise nature and status of the continuity assumption may have contributed to possible confusion within the field. In addition, recent empirical and conceptual advances in the analysis of derived relational responding suggest that a fresh look at the issue of continuity may be warranted.

The present paper will first outline the traditional behavior-analytic view of nonhuman-human ${ }^{1}$ continuity and highlight its pragmatic research features. Next, we will summarize the predominant use of the continuity assumption in research on basic tasks such as schedules of reinforcement and discuss the role it has played in recent discussions of nonhuman-human differences. Then, we will explore the possibility that behavioral principles different from those already discovered in research with nonhumans may be needed to explain complex human behavior, most notably in the experimental analysis of verbal behavior and derived stimulus relations. Finally, we will conclude with a pragmatic view of the future of the continuity assumption.

'Consistent with Dess and Chapman's (1998) suggested usage, we will use the terms human and nonhuman throughout the present article. 


\section{Behavior Analysis and The Continuity Assumption}

In "The Descent of Man," Charles Darwin proclaimed that "there is no fundamental difference between man and the higher mammals in their mental faculties" (Darwin, 1871, p. 446), thereby establishing continuity between nonhumans and humans. Darwin's followers further emphasized this assertion. For instance, Romanes provided anecdotal material that displayed instances of purposive action and intelligence on the part of animals, and Morgan suggested his canon of parsimony (Boring, 1929). The assumption of continuity between humans and nonhumans can be attributed, in large part, to the endeavors of these founders of comparative psychology, that being, the division of psychology concerned with comparisons of different species (Alcock, 1998; Hodos \& Campbell, 1969). As the founder of the American pragmatic tradition known as functionalism, William James (1890) further declared the similarities between humans and nonhumans:

Although our treatment must be hypothetical, this does not prevent it from being continuous. The point which as evolutionists we are bound to hold fast to is that all the new forms of being that make their appearance are really nothing more than results of the redistribution of the original and unchanging materials. (p. 146)

James pronounced his awe for the continuity assumption: "So strong a postulate is continuity! . . The demand for continuity has, over large tracts of science, proved itself to possess true prophetic power" (James, 1890 , p. 148). The historical development of behavior analysis can be traced through these foregoing influences. Specifically, functionalism, with its emphasis on behavior-environment relationships, the philosophy of pragmatism, with its rejection of a correspondence-based theory of truth, and evolutionary biology, all assumed a continuity of behavioral processes across species without denying the possibility of principles unique to humans (Boakes, 1984; Lattal, 2001; Morris, 1993). Accordingly, the study of nonhuman behavior was intended to elucidate behavioral differences with distantly related species such as humans.

In behavior analysis, the current approach to continuity emphasizes similarities between species by using "a few convenient species to study aspects of human behavior that are not amenable to experimental study for ethical and other reasons." (Harrison, 1994, p. 210, italics added). Skinner (1938) also approached the use of nonhumans in behavioral research as a matter of convenience:

In the broadest sense a science of behavior should be concerned with all kinds of organisms, but it is reasonable to limit oneself, at least in the beginning, to a single representative example. Through a certain anthropocentricity of interests we are likely to choose an organism that is as similar to man as is consistent with experimental convenience and control. (p. 47) 
Additional pragmatic factors such as the low cost of care and housing (Skinner, 1938, pp. 47-48; 1953, p. 38) made rats the "representative animal" (Harrison, 1994) for behavior-analytic research. Other rodents, pigeons, and primates were later employed as subjects as a means of establishing processes common to all species.

Traditionally, nonhuman research was predicated on the central assumption that a continuity of basic behavioral processes exists between nonhumans and humans (Branch \& Hackenberg, 1998). Research with nonhumans was intended to identify general principles of behavior applicable to all species. It was reasoned that by beginning with controlled experimental investigations of nonhuman behavior it should be possible to extrapolate to more complex human behavior (e.g., Skinner, 1938, 1953). According to Hodos and Campbell (1969), for instance, studying distantly related species is "very useful in formulating generalizations about behavioral adaptations to specific problems of survival. Such generalizations might have broad applicability to a number of lineages of the phylogenetic tree and would greatly aid in the interpretation of data obtained through the phylogenetic approach" ( $p$. 347). Indeed, the assumption of continuity has been supported well to date in the identification of our entire battery of behavioral principles. Reinforcement, punishment, generalization, discrimination, extinction, recovery, habituation, and so on, have all been demonstrated extensively with both human and nonhuman populations. Those that adhere to the continuity assumption expect to find, therefore, that all other behavioral principles identified with nonhumans will also be applicable to humans.

Behavior analysts such as Skinner were clear from the outset that they were not interested in nonhuman behavior per se, but rather in what it could tell us about human behavior (e.g., Keller \& Schoenfeld, 1950, p. 2; Skinner, 1938, pp. 441-442; 1953, p. 38). Assuming continuity between the behavior of nonhumans and humans readily allows for the identification of genuine species differences, should they exist, and thus "it is only by studying the behavior of lower animals that we can tell what is distinctly human" (Skinner, 1969, p. 101). However, to many outside the field, nonhumans were simply not older versions of humans and similarity of psychological processes between species could not be assumed nor could innate physiological differences be denied (Hayes, 1987). Skinner (1938) was patently aware, however, that the continuity strategy may or may not pay off. In his own words:

Whether or not extrapolation (from the behavior of the rat) is justified cannot at present be decided. It is possible that there are properties of human behavior which will require a different kind of treatment. (p. 442)

This early Skinnerian view involves treating continuity not as a fundamental postulate but as an epistemological tool or research strategy (Hayes, 1987; Hayes et al., 2001a; Hayes \& Hayes, 1992). The key issue 
from this perspective, then, is not whether specific similarities or differences really exist between species, but whether a working assumption of continuity of behavioral processes will lead to greater prediction and influence of human behavior. This form of the continuity strategy is both pragmatic and parsimonious in that it provides a convenient starting point for a science of behavior without ruling out the possibility of revealing differences in the analysis of human behavior. Importantly, however, because it is not a fundamental philosophical tenet of behaviorism, the continuity strategy could be abandoned immediately without jeopardizing the experimental analysis of behavior.

Although not essential to behavior analysis, the continuity assumption has turned out to be a remarkably effective strategy of immense practical benefit to the field. The basic principles of reinforcement, punishment, and discrimination have been demonstrated using virtually every mammalian and avian species and have been further replicated with a variety of invertebrate species. Early work with humans (e.g., Ayllon \& Michael, 1959; Fuller, 1949; Lindsley, 1960) provided further empirical support for continuity, whereas many of the techniques and procedures used in applied behavior analysis today were originally derived, in large part, from research with nonhumans (Mace, 1994; Miltenberger, 2001). It seems, therefore, that assuming continuity has allowed researchers to develop a number of basic behavioral principles and to examine the applicability of those principles to the prediction and control of human behavior in laboratories and real-world settings. In fact, the success of the continuity assumption may help to explain why it is so highly valued within the behavioral tradition. However, not all behavioral researchers are willing to swear allegiance to the flag of continuity, and in some cases this useful strategic assumption has become the target of different research programs designed to support or undermine its credibility, and it is to this issue we now turn.

\section{Applying and Misapplying the Continuity Research Strategy}

One way in which the continuity strategy has been targeted is in comparing human behavior with the benchmark of nonhuman behavior by undertaking procedural comparisons (Perone, Galizio, \& Baron, 1988). From this perspective, basic research with humans is intended to confirm the relevance and replicability of behavioral principles already identified in nonhuman research prior to their application to issues of social significance in natural settings. Researchers concerned with this issue, most notably in the study of human operant performance on schedules of reinforcement, often describe human behavior as being "sensitive" to the programmed contingencies when performance resembles that of nonhumans under similar contingencies (e.g., Navarick, Bernstein, \& Fantino, 1990). Human analogs of nonhuman operant chambers and other procedural comparisons, including providing food reinforcement, have been employed by researchers attempting to make contingencies 
structurally and functionally similar across species. In the light of recent research, however, this extreme form of the continuity strategy has led to a degree of conceptual confusion in both accounting for species differences in behavior and in defining exactly what a "difference" entails. For instance, Madden, Chase, and Joyce (1998) provide a cogent review of the difficulties inherent in undertaking between-species comparisons of performance on schedules of reinforcement and the confusion that results when using the term sensitivity to describe behavior. They outline the following three difficulties with between-species comparisons.

First, using nonhuman behavior as a benchmark for human behavior relies upon the assumption that the schedule performance of nonhumans in some way represents "schedule-typical" behavior. However, different nonhuman species have shown different response patterns on fixedinterval (FI) schedules (Ferster \& Skinner, 1957, p. 157) and performance differences along other measures (Perone et al., 1988). Taken together, this suggests that the fixed-interval scallop may not be as characteristic of $\mathrm{FI}$ nonhuman behavior as was previously assumed (Hyten \& Madden, 1993; Perone et al., 1988), but also that using any definition of typical nonhuman behavior as a benchmark for between-species comparisons is likely to be unfounded and lead to further confusion. Second, behavior is not always consistent between nonhuman species. Any differences between same or different species do not permit general conclusions to be made about the sensitivity or nonsensitivity of human behavior (Baron, Perone, \& Galizio, 1991; Perone et al., 1988). Finally, by making between-species comparisons one is assuming that "procedures employed with humans and nonhumans that are structurally similar across species will be functionally similar as well. According to this logic, all experimental procedures that resemble those controlling nonhuman behavior must also control human behavior in the same manner. This conclusion, however, ignores the possibility that procedures that are structurally similar across experiments may produce functional differences across species" (Madden et al., 1998, p. 5). Importantly, this conclusion poses a challenge to the traditional assumptions of continuity by drawing attention to the role played by possible procedural differences in accounting for between-species discrepancies. According to Branch and Hackenberg (1998), "it is important to study human and nonhuman behavior under circumstances as similar as possible. Otherwise, differences in performance may be mistakenly attributed to human verbal functioning or some species-typical characteristic, when they are actually the result of more mundane differences in procedure." (p. 27). In this way, an extreme form of the continuity strategy is preserved by clutching onto the battery of existing behavioral principles and then seeking to determine how, procedurally, they apply to human behavior.

This cautious stance has flourished despite research frequently demonstrating differences between nonhuman and human behavior using structurally and functionally similar contingencies and environmental contexts. These near-ubiquitous findings have led some 
researchers to propose that different behavioral principles might be needed to account for differences in nonhuman and human behavior (e.g., Lowe, 1979, 1983), thereby abandoning the continuity strategy. Based on the findings of research on reinforcement schedules, Lowe sought to explain human and nonhuman differences on $\mathrm{FI}$ and other schedules, not by speculating on the ways in which the behavioral principles worked with humans or the possible influence of procedural factors, but by postulating that new principles must exist for human behavior. Thus, it seems that the extreme form of the continuity strategy has led some human operant researchers to abandon it entirely. The success of the strategy, at least to Lowe (1979), has been its downfall. But what is the alternative?

Whereas the past 80 years of behavior-analytic research has supported the continuity view, recently the assumption of anti-continuity has gained momentum, particularly in the experimental analysis of human verbal behavior. Species differences are typically explained in terms of the effect of verbal behavior on human performance; the socalled "language hypothesis" (cf. Barnes, 1989; Lowe, 1979). For many, the language hypothesis made the study of human verbal behavior essential in its own right (e.g., Hayes, Blackledge, \& Barnes-Holmes, 2001; Hayes \& Hayes, 1992). Indeed, it could be argued that the continuity strategy has in fact been misapplied within the context of human operant research. The strategy provided a useful assumption underpinning the use of nonhumans in the behavioral laboratory, but the strategy was never meant to be, at least within behavior analysis, the key focus of the research agenda. However, when human participants demonstrated response patterns on schedules of reinforcement that differed from nonhumans, the battle lines were quickly drawn between the continuity strategists and proponents of the language hypothesis. The former sought to demonstrate that procedural variables alone could explain the behavioral differences, whereas the latter looked to the development of human language as the important source underlying the differing behavioral outcomes across human and nonhuman species.

We would argue that this empirical concern with the continuity strategy was unfortunate because it served to distract behavioral researchers from the systematic study of human behavior in its own right (Barnes, 1989; Hayes \& Hayes, 1989). Rather than creating a rich and varied program of behavior-analytic research on human behavior, many of the studies focused instead on demonstrating that humans produced schedule performances that were either similar or dissimilar to nonhumans (e.g., Baron et al., 1991; Lowe, 1979; Lowe, Beasty, \& Bentall, 1983; Lowe, Harzem \& Bagshaw, 1978; Perone et al., 1988). Despite over two decades of research, this issue remains largely unresolved within the context of schedule research, and one now rarely sees an article on human reinforcement schedule performance that attempts to deal directly with the issue of continuity.

Unfortunately, however, the battle between the respective proponents of 
the continuity strategy and the language hypothesis continues to this day, but the theater of controversy is now provided through the study of equivalence and other derived stimulus relations rather than through the study of reinforcement schedules. In the remainder of this article we will briefly examine the study of derived stimulus relations, and three different theoretical approaches that have emerged within this domain. Two of these approaches clearly stand on opposite sides of the continuity fence, whereas the third self-consciously attempts to avoid the debate, focusing instead on the study of human behavior as an important research topic in its own right.

\section{Derived Relational Responding and the Continuity Strategy}

Over the past 30 years, behavior analysts have devoted considerable research attention to the phenomenon of derived stimulus relations that appear to provide the foundations for a modern behavioral account of verbal behavior. The basic finding is as follows. Suppose, for instance, reinforcement is delivered for selection of the following arbitrary stimuli on separate trials: $B$ in the presence of stimulus $A$, and $C$ in the presence of stimulus $B$. Most verbally able humans will now readily reverse these explicitly reinforced conditional discriminations in the absence of further training. That is, they will now select $A$ given $B$, and $B$ given $C$ in accordance with derived symmetrical, or mutually entailed, stimulus relations. Furthermore, subjects will now also select $C$ given $A$ and $A$ given $C$ in accordance with derived transitive and equivalence, or combinatorially entailed, stimulus relations without further training. Following such derived performances, the stimuli are said to participate in an equivalence class (Sidman, 1994) or a relational frame of equivalence (Barnes, 1994; Hayes, 1991). Perhaps what is most interesting about derived stimulus relations such as equivalence is that the outcomes are not readily predicted from the traditional concept of conditional discrimination; neither $\mathrm{A}$ nor $\mathrm{C}$ has a direct history of differential reinforcement with regard to the other, and therefore neither stimulus should control selection of the other. Similarly, the processes responsible for these outcomes can not be based upon stimulus generalization because the stimuli have no formal properties in common.

Another feature of derived stimulus relations is the transformation of stimulus functions among related stimuli. The transformation of stimulus functions is said to occur when the function of one stimulus in a derived relation alters or transforms the functions of another according to the derived relation between the two, without additional training. Derived stimulus functions have been demonstrated with children, adults, and individuals with developmental disabilities using discriminative, consequential, and respondent eliciting, extinction, and avoidance functions (for a review see Dymond \& Rehfeldt, 2000). Such findings are important because they make derived relational responding relevant to psychology in general and because the transformation of arbitrary relational functions can lead to other forms of responding. Indeed, it has 
been argued that the transformation of functions may provide a contemporary behavior-analytic account of the processes through which stimuli come to acquire novel functions, both adaptive and abberant, via verbal processes (e.g., Barnes-Holmes, Hayes, \& Dymond, 2001; Friman, Hayes, \& Wilson, 1998; Roche \& Barnes, 1997; Wilson \& Hayes, 2000 ). For many behavior analysts, it is now possible to define verbal events in terms of derived stimulus functions and thus build upon Skinner's (1957) account of verbal behavior in accounting for the generative and referential nature of human language (see, for example, Barnes-Holmes, Barnes-Holmes, \& Cullinan, 2000).

\section{Derived Relational Responding and Species Differences}

Derived stimulus relations appear to have many implications for providing a functional analysis of human language and cognition. One of the main empirical reasons why the phenomenon of derived stimulus relations has been implicated in the analysis of human language and cognition is the unrelenting difficulty researchers have experienced in demonstrating it with nonhuman species, including higher primates (e.g., Dugdale \& Lowe, 2000; Sidman, Rauzin, Lazar, Cunningham, Tailby, \& Carrigan, 1982; but see L. J. Hayes, 1992; Kastak, Schusterman, \& Kastak, 2001; Schusterman \& Kastak, 1993). The relative ease with which derived stimulus relations emerge for humans compared with the difficulty reported in obtaining similar results from nonhuman experiments, even following extensive training (e.g., Dube, Mcllvane, Callahan, \& Stoddard, 1993; Dugdale \& Lowe, 2000; Hayes, 1989; Lipkens, Kop, \& Matthijs, 1988), has been seen by some as threatening the continuity strategy, at least within the behavior-analytic tradition. As indicated previously, this threat to the continuity strategy appears to have generated three different theoretical positions within the study of derived stimulus relations, reflecting pro-continuity, anti-continuity, and an agnostic stance. We will briefly consider each of these in turn.

The pro-continuity position is best reflected in theoretical work of Sidman $(1994,2000)$ and his colleagues (e.g., Mcllvane, Serna, Dube, \& Stromer, 2000). These researchers have argued explicitly that equivalence class formation, and perhaps other forms of derived relational responding, are basic stimulus functions that "fall out of" the reinforcement contingencies. Not unlike the pro-continuity schedule researchers from the 1970 s and 1980s, Sidman and colleagues argue that the many failures to show derived stimulus relations with nonhumans is likely due to procedural problems that have not yet been corrected in any nonhuman study (see Mcllvane et al., 2000, for a detailed discussion of this issue).

The anti-continuity position is best reflected in the "naming" account of equivalence, which argues that an individual's naming skills are necessary and may be sufficient for passing tests of emergent relations and hence nonhumans that lack such naming skills will fail to demonstrate equivalence (Horne \& Lowe, 1996). The fact that nonhumans have yet to convincingly show derived relational responding is often cited as evidence for this 
position. Indeed, Horne and Lowe (1996) go so far as to suggest that even if a nonhuman species were to pass, unequivocally, tests for equivalence then such results would not aid our understanding of human behavior as the processes involved would necessarily be contingency-shaped and not verbally governed ( $p$. 224). This explanation of species differences presupposes the existence of additional behavioral principles in human behavior and explicitly abandons the gains of the continuity strategy, replacing it with ill-defined, "language-centric" terms (see Barnes, 1996; Stromer, Mackay, \& Remington, 1996).

The agnostic position, with respect to the continuity assumption, is clearly reflected in Relational Frame Theory ${ }^{2}$ (see Hayes, Barnes-Holmes, \& Roche, 2001b). This theoretical position considers equivalence and other derived stimulus relations to be learned behavior, or more specifically a new type of generalized relational operant. According to this view, relational operants themselves can become generalized to a wide variety of stimulus and response events, in a broadly similar way as occurs in generalized imitation (see Barnes-Holmes \& Barnes-Holmes, 2000). The operant process of relational framing is new insofar as it can affect how all other behavioral processes work (Hayes et al, 2001b). An explicitly reinforced punisher, for example, can be transformed almost instantly into a reinforcer if it comes to participate in a derived stimulus relation of opposition with punishment (e.g., as when a child is told during a game that "good means bad and bad means good"). Although RFT argues that a new behavioral process is involved in derived relational responding, RFT remains agnostic with respect to the continuity assumption in that it does "not need to take the stand that nonhumans will never show derived stimulus relations." (Hayes, Barnes-Holmes, \& Roche, 2001a, p. 145). In short, there may or may not be continuity in terms of derived relational responding from nonhuman to human, but in and of itself this issue is relatively unimportant for RFT.

Nonetheless, questions concerning nonhuman-human continuity can emerge from RFT. For example, one might ask, is there a level of derived relational responding that nonhumans can not reach? Intuitively, some limit on nonhuman derived relational responding seems almost certain, but discovering this limit is not a key focus for the theory. And in any case, it would be a quantitative limit on the behavioral process of relational framing, not evidence for a new process specific to humans. With that said, work with nonhumans may well be critical in disentangling the behavioral histories involved in establishing and manipulating relational framing as an operant behavior. In fact, the well-known study by Schusterman and Kastak (1993), in which multiple-exemplar training was used to establish equivalence responding in a sea lion, provides strong evidence to support the RFT interpretation of stimulus equivalence as a generalized operant response class.

${ }^{2}$ Relational frame theory is but one example of a research area in behavior analysis that remains agnostic with respect to the continuity assumption. The study of rule-governed behavior, for instance, could also be characterized in this way. However, we have focused on RFT for present purposes because it is very clearly and explicitly agnostic on the continuity issue (see Hayes, Barnes-Holmes, \& Roche, 2001a, p. 145). 
In the final analysis, RFT assumes that the behavioral differences between nonhumans and humans will largely be quantitative in nature. An important task for RFT is to predict and control this quantitative difference by exploring the reinforcement histories that give rise to complex human behavior. Nonhuman research is one way in which this can be undertaken. For instance, how much training is necessary and with how many different stimulus combinations, before relational responding becomes abstracted and generalizes to novel stimulus sets? These and other empirical issues can, and should, be examined with both nonhumans and humans (for examples of this approach see, Giurfa, Zhang, Jenett, Menzel, \& Srinivasan, 2001; Kastak et al., 2001; Zentall, 1998; Zentall \& Urcuoli, 1993). Although nonhumans have yet to demonstrate, unequivocally, derived relational responding, studying the extent to which nonhuman and human behavior differs should help to identify both the reinforcement history necessary to establish the desired performance and highlight the advantages of studying human behavior on its own terms (Hayes, Blackledge, et al., 2001). The continuity strategy will provide a possibly useful backdrop for this work, but it will not be the key focus of the research activity. In this way, RFT removes itself from the pro- and anti-continuity battle, and turns instead to the analysis of human behavior in its own right, employing humans, nonhumans, and even computational models (e.g., Barnes \& Hampson, 1997), in its quest to provide a modern behavioral understanding of human language and cognition.

\section{Conclusion}

The strategic nature of the continuity assumption can encourage researchers to investigate human behavior in its own right, but it can also encourage research that seems entirely focused on proving or disproving the assumption. We are not convinced that this latter approach has been particularly productive or progressive as a research strategy. Quantifying human-nonhuman differences necessitates that we look beyond the traditional behavioral explanation of "enormous differences in complexity" (Skinner, 1938, p. 442) and undertake, for example, further empirical and conceptual analyses of derived relational responding. If human behavior, and language and cognition in particular, can not be understood in terms of processes that are also observed in nonhuman behavior, then it means simply that processes emerged in one evolutionary branch and not another. Behavior analysis, as an approach to psychology, will not stand or fall on this issue. In fact, the continuity strategy was never meant to be the key focus of any behavior-analytic research agenda, and as such we should not target this strategy as one of our main concerns in the study of human behavior. We believe that there are just too many other more important issues to be addressed in the study of human psychology. 


\section{References}

ALCOCK, J. (1998). Animal behavior (6th ed.). Sunderland, MA: Sinauer.

AYLLON, T., \& MICHAEL, J. (1959). The psychiatric nurse as a behavioral engineer. Journal of the Experimental Analysis of Behavior, 2, 323-334.

BARNES, D. (1989). Behavior-behavior analysis, human schedule performance, and radical behaviorism. The Psychological Record, 39, 339-350.

BARNES, D. (1994). Stimulus equivalence and relational frame theory. The Psychological Record, 44, 91-124.

BARNES, D. (1996). Naming as a technical term: Sacrificing behavior analysis at the altar of popularity? Joumal of the Experimental Analysis of Behavior, 65, 264-267.

BARNES, D., \& HAMPSON, P. J. (1997). Connectionist models of arbitrarily applicable relational responding: A possible role for the hippocampal system. In J. Donahoe \& V. P. Dorsel (Eds.), Neural-network models of cognition (pp. 496-521). North-Holland: Elsevier.

BARNES-HOLMES, D., \& BARNES-HOLMES, Y. (2000). Explaining complex behavior: Two perspectives on the concept of generalized operant classes. The Psychological Record, 50, 251-265.

BARNES-HOLMES, D., BARNES-HOLMES, Y., \& CULLINAN, V. (2000). Relational frame theory and Skinner's Verbal Behavior. A possible synthesis. The Behavior Analyst, 23, 69-84.

BARNES-HOLMES, D., HAYES, S. C., \& DYMOND, S. (2001). Self and selfdirected rules. In S. C. Hayes, D. Barnes-Holmes, \& B. Roche (Eds.), Relational frame theory: A post-Skinnerian account of human language and cognition (pp. 119-139). New York: Plenum Press.

BARON, A., PERONE, M., \& GALIZIO, M. (1991). The experimental analysis of human behavior: Indispenable, ancillary, or irrelevant? The Behavior Analyst, 14, 145-155.

BOAKES, R. (1984). From Darwin to behaviorism: Psychology and the minds of animals. Cambridge: University Press.

BRANCH, M. N., \& HACKENBERG, T. D. (1998). Humans are animals, too: Connecting animal research to human behavior and cognition. In W. O'Donohue (Ed.), Leaming and behavior therapy (pp. 15-35). Boston: Allyn \& Bacon.

BORING, E. G. (1929). A history of experimental psychology. New York: Appleton-Century-Crofts, inc.

DARWIN, C. (1871). The descent of man. London: John Murray.

DESS, N. K., \& CHAPMAN, C. D. (1998). Humans and animals? On saying what we mean. Psychological Science, 9, 79-80.

DUBE, W. V., MCILVANE, W. J., CALLAHAN, T. D., \& STODDARD, L. T. (1993). The search for stimulus equivalence in nonverbal organisms. The Psychological Record, 43, 761-778.

DUGDALE, N., \& LOWE, C. F. (2000). Testing for symmetry in the conditional discriminations of language-trained chimpanzees. Journal of the Experimental Analysis of Behavior, 73, 5-22.

DYMOND, S., \& REHFELDT, R. (2000). Understanding complex behavior: The transformation of stimulus functions. The Behavior Analyst, 23, 239-254.

FERSTER, C. B., \& SKINNER, B. F. (1957). Schedules of reinforcement. New York: Appleton-Century Crofts.

FRIMAN, P. C., HAYES, S. C., \& WILSON, K. G. (1998). Why behavior analysts should study emotion: The example of anxiety. Journal of Applied Behavior Analysis, 31, 137-156. 
FULLER, P. R. (1949). Operant conditioning of a vegetative human organism. American Journal of Psychology, 62, 587-590.

GIURFA, M., ZHANG, S., JENETT, A., MENZEL, R., \& SRINIVASAN, M. V. (2001). The concepts of sameness and difference in an insect. Nature, 410, 930-933.

HARRISON, J. M. (1994). The representative animal. The Behavior Analyst, 17, 207-219.

HAYES, L. J. (1992). Equivalence as process. In S. C. Hayes \& L. J. Hayes (Eds.), Understanding verbal relations (pp. 97-108). Reno, NV: Context Press.

HAYES, S. C. (1987). Upward and downward continuity: It's time to change our strategic assumptions. Behavior Analysis (APA Division 25 Newsletter), 22, 3-6.

HAYES, S. C. (1989). Nonhumans have not yet shown stimulus equivalence. Journal of the Experimental Analysis of Behavior, 51, 385-392.

HAYES, S. C. (1991). A relational control theory of stimulus equivalence. In L. J. Hayes \& P. N. Chase (Eds.), Dialogues on verbal behavior: The first international institute on verbal relations (pp. 19-40). Reno, NV: Context Press.

HAYES, S. C., BARNES-HOLMES, D., \& ROCHE, B. (2001a). Relational frame theory: A précis. In S. C. Hayes, D. Barnes-Holmes, \& B. Roche (Eds.), Relational frame theory: A post-Skinnerian account of human language and cognition (pp. 141-154). New York: Plenum Press.

HAYES, S. C., BARNES-HOLMES, D, \& ROCHE, B. (2001b). Relational frame theory: A post-Skinnerian account of human language and cognition. New York: Plenum.

HAYES, S. C., BLACKLEDGE, J. T., \& BARNES-HOLMES, D. (2001). Language and cognition: Constructing an alternative approach within the behavioral tradition. In S. C. Hayes, D. Barnes-Holmes, \& B. Roche (Eds.), Relational frame theory: A post-Skinnerian account of human language and cognition (pp. 3-20). New York: Plenum Press.

HAYES, S. C., FOX, E., GIFFORD, E. V., WILSON, K. G., BARNES-HOLMES, D., \& HEALY, O. (2001). Derived relational responding as learned behavior. . In S. C. Hayes, D. Barnes-Holmes, \& B. Roche (Eds.), Relational frame theory: A post-Skinnerian account of human language and cognition (pp. 21-50). New York: Plenum Press.

HAYES, S. C., \& HAYES, L. J. (1989). The verbal action of the listener as a basis for rule-governance. In S. C. Hayes (Ed.), Rule-governed behavior: Cognition, contingencies, and instructional control (pp. 153-190). New York: Plenum Press.

HAYES, S. C., \& HAYES, L. J. (1992). Verbal relations and the evolution of behavior analysis. American Psychologist, 47, 1383-1395.

HODOS, W., \& CAMPBELL, C. B. G. (1969). Scala naturae: Why there is no theory in comparative psychology. Psychological Review, 76, 337-350.

HORNE, P. J., \& LOWE, C. F. (1996). On the origins of naming and other symbolic behavior. Journal of the Experimental Analysis of Behavior, 65, 185-242.

HYTEN, C., \& MADDEN, G. J. (1993). The scallop in human fixed-interval research: A review of problems with data description. The Psychological Record, 43, 471-500.

JAMES, W. (1890). The principles of psychology, Volume 1. New York: Dover Publications, Inc.

KASTAK, C. R., SCHUSTERMAN, R. J., \& KASTAK, D. (2001). Equivalence classification by California sea lions using class-specific reinforcers. Journal of the Experimental Analysis of Behavior, 76, 131-158.

KELLER, F. S., \& SCHOENFELD, W. N. (1950). Principles of psychology. New York: Appleton Century Crofts. 
LATTAL, K. A. (2001). The human side of animal behavior. The Behavior Analyst, 24, 147-161.

LINDSLEY, O. R. (1960). Characteristics of the behavior of chronic psychotics as revealed by free-operant conditioning methods. Diseases of the Nervous System Monograph Supplement, 21, 66-78.

LIPKENS, R., KOP, P. F. M., \& MATTHIJS, W. (1988). A test for symmetry and transitivity in the conditional discrimination performances of pigeons. Journal of the Experimental Analysis of Behavior, 49, 395-409.

LOWE, C. F. (1979). Determinants of human operant behavior. In M. D. Zeiler \& P. Harzem (Eds.), Reinforcement and the structure of behavior (pp. 159192). New York: Wiley \& Sons.

LOWE, C. F. (1983). Radical behaviorism and human psychology. In G. C. L. Davey (Ed.), Animal models of human behavior (pp. 71-93). London:Wiley.

LOWE, C. F., BEASTY, A., \& BENTALL, R. P. (1983). The role of verbal behavior in human learning: Infant performance on fixed-interval schedules. Journal of the Experimental Analysis of Behavior, 39, 157-164.

LOWE, C. F., HARZEM, P., \& BAGSHAW, M. (1978). Species differences in temporal control of behavior II: Human performance. Journal of the Experimental Analysis of Behavior, 29, 351-361.

MACE, F. C. (1994). Basic research needed for stimulating the development of behavioral technology. Journal of the Experimental Analysis of Behavior, 61, 529-550.

MADDEN, G. J., CHASE, P. N., \& JOYCE, J. H. (1998). Making sense of sensitivity in the human operant literature. The Behavior Analyst, 21, 1-12.

MCILVANE, W. J., SERNA, R. W., DUBE, W. V., \& STROMER, R. (2000). Stimulus control topography coherence and stimulus equivalence: Reconciling test outcomes with theory. In J. C. Leslie \& D. Blackman (Eds.), Experimental and applied analyses of human behavior (pp. 85-110). Reno, NV: Context Press.

MILTENBERGER, R. G. (2001). Behavior modification: Principles and procedures (2nd ed.). Belmont, CA: Wadsworth/Thomson Learning.

MORRIS, E. K. (1993). Contextualism, historiography, and the history of behavior analysis. In S. C. Hayes, L. J. Hayes, H. W. Reese, \& T. R. Sarbin (Eds.), Varieties of scientific contextualism (pp. 137-165). Reno, NV: Context Press.

NAVARICK, D. J., BERNSTEIN, D. J., \& FANTINO, E. (1990). The experimental analysis of human behavior. Journal of the Experimental Analysis of Behavior, 54, 159-162.

PERONE, M., GALIZIO, M., \& BARON, A. (1988). The relevance of animal-based principles in the laboratory study of human operant conditioning. In $G$. Davey \& C. Cullen (Eds.), Human operant conditioning and behavior modification (pp. 59-85). New York: Wiley.

ROCHE, B., \& BARNES, D. (1997). A transformation of respondently conditioned sexual arousal functions in accordance with arbitrary relations. Journal of the Experimental Analysis of Behavior, 67, 275-301.

SCHUSTERMAN, R. J., \& KASTAK, D. (1993). A Califonia sea lion (Zalophus californianus) is capable of forming equivalence relations. The Psychological Record, 43, 823-839.

SKINNER, B. F. (1938). The behavior of organisms. New York: Appleton-Century Crofts. SKINNER, B. F. (1953). Science and human behavior. New York: Free Press.

SKINNER, B. F. (1957). Verbal behavior. New York: Appleton-Century Crofts.

SKINNER, B. F. (1969). Contingencies of reinforcement: A theoretical analysis. New York: Appleton Century Crofts. 
SIDMAN, M. (1994). Equivalence relations and behavior: A research story. Boston, MA: Author's Cooperative.

SIDMAN, M. (2000). Equivalence relations and the reinforcement contingency. Journal of the Experimental Analysis of Behavior, 74, 127-146.

SIDMAN, M., RAUZIN, R., LAZAR, R., CUNNINGHAM, S., \& TAILBY, W., \& CARRIGAN, P. (1982). A search for symmetry in the conditional discriminations of rhesus monkeys, baboons, and children. Journal of the Experimental Analysis of Behavior, 37, 23-44.

STROMER, R., MACKAY, H. A., \& REMINGTON, B. (1996). Naming, the formation of stimulus classes, and applied behavior analysis. Journal of Applied Behavior Analysis, 29, 409-431.

WILSON, K. G. \& HAYES, S. C. (2000). Why it is crucial to understand thinking and feeling: An analysis and application to drug abuse. The Behavior Analyst, 23, 25-43.

ZENTALL, T. R. (1998). Symbolic representation in animals: Emergent stimulus relations in conditional discrimination learning. Animal Learning \& Behavior, 26, 363-377.

ZENTALL, T. R., \& URCUIOLI, P. J. (1993). Emergent relations in the formation of stimulus classes in pigeons. The Psychological Record, 43, 795-810. 
DYMOND ET AL. 